\title{
Polifonia na Produção do Binarismo de Gênero em Brincadeiras na Primeira Infância
}

\author{
André Pereira dos Santos ${ }^{1}$ \\ ${ }^{1}$ Universidade de Brasília, DF, Brasil. \\ Silviane Bonaccorsi Barbato ${ }^{1}$ \\ ${ }^{1}$ Universidade de Brasília, DF, Brasil. \\ Polianne Delmondez ${ }^{1}$ \\ ${ }^{1}$ Universidade de Brasília, DF, Brasil.
}

\begin{abstract}
Resumo: Estudos sobre desenvolvimento de identificação de gênero têm indicado a presença de estereotipias na escolha de cores, brinquedos e objetos nos primeiros três anos de vida, suscitando discussões sobre método. O objetivo deste artigo é analisar o uso de objetos e sua relação com dinâmicas polifônicas na produção de significados de gênero em brincadeiras. Foram utilizados multimétodos qualitativos com foco em interações diádicas (criança-objeto) e triádicas (adulto-criança-objeto) com quatro meninas de 30 a 36 meses. Uma etapa de entrevista com as cuidadoras também foi incluída. Os dados foram submetidos à análise dialógica temática e relacionados às expectativas de gênero convencionais. Os resultados indicam como os processos de convencionalização ocorrem nas interações orientados para a manutenção do binarismo como dinâmica dominante na produção de subjetividades, em brincadeiras que envolvem: ações de cuidar de si e do outro; regulação de significados e usos de objetos pelas cuidadoras orientadas para o convencional; e ambivalências entre enunciados de gênero.
\end{abstract}

Palavras-chave: Primeira Infância, Polifonia, Produção de Significados, Multimétodo, Binarismo de Gênero.

\section{Polyphony in the Production of Gender Binarism in Early Childhood Play}

\begin{abstract}
Studies on development of gender identification indicate the presence of stereotypes in the choice of colors, toys and objects in three year-olds, provoking discussions about method. This article aims to analyze the use of objects and their relation to polyphonic dynamics in the production of meanings of gender in play. Four girls aged 30 to 36 months took part in qualitative multimethod sessions with a focus on dyadic (child-object) and triadic (adult-child-object) interactions. Caregivers took part in an individual semi-structured interview. Data were submitted to a thematic dialogic analysis and related to conventional gender expectations. Results indicated that conventionalization processes occur in interactions oriented to the maintenance of binarism as a dominant dynamics in the production of subjectivities in early childhood in Brazil, in play that involves: actions of caring for oneself and the other; caregivers' regulation of meanings and objects towards a permanence of gender stereotypes; and ambivalences that may indicate change in course.
\end{abstract}

Keywords: Early Childhood, Polyphony, Production of Meanings, Multimethod, Gender Binarism. 


\title{
Polifonía en la Producción del Binarismo de Género en Juegos en la Primera Infancia
}

\begin{abstract}
Resumen: Los estudios sobre desarrollo de identificación de género han indicado la presencia de estereotipias en la elección de colores, juguetes y objetos en los primeros tres años de vida, suscitando discusiones sobre método. El objetivo de este artículo es analizar el uso de objetos y su relación con dinámicas polifónicas en la producción de significados de género en juegos. Cuatro niñas de 30 a 36 meses participaron de un estudio con uso de multimétodos cualitativos con foco en interacciones diádicas (niño-objeto) y triádicas (adulto-niño-objeto). Una etapa de entrevista con las cuidadoras también fue incluida. Los datos fueron sometidos al análisis dialógico temático y relacionados a las expectativas de género convencionales. Los resultados indican que los procesos de convencionalización ocurren en las interacciones orientadas hacia la permanencia del binarismo como dinámica dominante en la producción de subjetividades, en juegos en la primera infancia en Brasil que implican: acciones de cuidar de sí y del otro; la regulación de significados y de objetos por las cuidadoras orientadas a la permanencia de los estereotipos; $\mathrm{y}$ ambivalencias entre enunciados de género que pueden indicar cambios.
\end{abstract}

Palabras clave: Primera Infancia, Polifonía, Producción de Significados, Multimétodo, Binarismo de Género.

Estudos sobre desenvolvimento de identificação de gênero têm indicado que as estereotipias em escolhas de cores, brinquedos e objetos são observadas antes dos três anos de idade (Bigler, 1997; Cowan, \& Hoffman, 1986; Navarro, Martinez, Yubero, \& Larrañaga, 2014; Robinson, \& Morris, 1986; Sprung, 1983; Wong, \& Hines, 2015). Considerando-se as discussões sobre a relação entre desenvolvimento e gênero na atualidade, neste artigo propomos analisar o uso de objetos na produção de significados de gênero em brincadeiras de quatro meninas de 30 a 36 meses, com a utilização de multimétodos.

As práticas culturais são produzidas com significados sedimentados e atualizados nas interações cotidianas. No seu desenvolvimento, a criança participa das práticas vigentes em seu grupo e interage com artefatos instrumentais e simbólicos, que podem indicar sentidos produzidos com os/as cuidadores/as em diferentes contextos. As práticas culturais são atualizadas no jogo entre permanências e mudanças, em que se observa a canalização de crenças e valores e a introdução de novos elementos de significação. Nas tensões dos espaços intersubjetivos, a comunalidade é produzida pelos interlocutores por acordos e quebras de comunicação que desencadeiam a negociação dos significados.

As dinâmicas polifônicas se dão em dialogia permeada por momentos fugazes de monologia (Barbato,
Mieto, \& Rosa, 2016) em que as múltiplas vozes (Volosinov, 2009), situacionais e históricas, concretizam-se nas atividades. Indicadores de mudança podem ser observados tanto em atuações inovadoras no brincar quanto na produção de ambivalências, "em que cada nova contextualização de um signo evoca algum tipo de discrepância" (Abbey, \& Valsiner, 2005, p. 4). As ambivalências são dinamogênicas, pois orientam a pessoa para novas formas de atuação e comunicação, podendo desencadear outras possibilidades de interpretações de si, do outro e do mundo.

$\mathrm{O}$ jogo entre dialogia-monologia nas interlocuções cuidador-criança pequena é observável quando a produção de sentidos, momentaneamente, desloca-se de forma fluida e fugaz do "espaço-entre" para um dos polos de interlocução que orienta as atuações-significações para a permanência, promovendo cristalizações no fluxo da atividade. Geralmente, a concretização de monologias ocorre na atuação de um dos interlocutores com mais poder e/ou conhecimento, evidenciando as assimetrias em andamento, em que há preferência pelo direcionamento das ações mediadas por usos específicos, canônicos, de artefatos, gestos e discursos marcados por interjeições, imperativos em gêneros discursivos que enfocam processos de convencionalização na aquisição e aprendizagem de conhecimentos (Barbato et al., 2016). 
O brincar, como atividade típica da infância, constitui um dos processos principais em que a criança se produz culturalmente (Barbato, \& Mieto, 2014; Benjamin, 2009; Correia, \& Meira, 2008; Vygotsky, 1978). É possível observar espaços de atualizações de discursos, de práticas sociais e de performances de gênero que ocorrem nas interações (Butler, 1993; Fausto-Sterling, 2012). Estas são produzidas em processos dialógicos com base em usos que se tornaram preferenciais na cultura ou, ainda, em espaços de inovações e transgressões de regras sociais (Bicalho, 2013).

As ações em brincadeiras contribuem para produzir significados de gênero (Bicalho, 2013; Fausto-Sterling, Coll, \& Lamarre, 2012; Furlan, \& Müller, 2015). Esta concepção sobre gênero atuaria a serviço da diferença sexual para constituir indivíduos concretos em homens e mulheres (Fagundes, 2001; Lauretis, 1987). No entanto, é importante observá-lo como produto cultural mediante processos de convencionalização historicamente constituídos.

O desenvolvimento do entendimento social das crianças ocorre em interações triádicas adulto-criança-objeto desde o nascimento (Palacios, \& Rodríguez, 2015; Palacios, Rodríguez, Méndez-Sánchez, \& Hermosillo de la Torre, 2013; Rodríguez, 2012). É durante a primeira infância, que importantes mudanças ocorrem no sentido educativo. Neste período, vários encontros se dão mediados por adultos, que atuam como "embaixadores entre o mundo e a criança” (Rodríguez, 2012, p. 24). Tais encontros promovem oportunidades de aprendizagem das propriedades sociais dos objetos e dos usos por sua função (Palacios, \& Rodríguez, 2015), processo este que chamamos de convencionalização.

As ações humanas são orientadas por processos de convencionalização (Bartlett, 1996), que pressionam o que não corresponde aos critérios semióticos da cultura, isto é, o arbitrário, não canônico, para algo que possa ser adotado por esta, tornando-se canônico, "normal" ou "natural" (Mieles, \& García, 2010). Neste texto, compreendemos o cânone como constituído a partir de estruturações e procedimentos básicos, que possibilitam a padronização de regras ou normas, orientam a conduta humana e se conduzem em direção às expectativas culturais (Bruner, 1997). Na infância, as crianças começam a usar objetos de modo não canônico, por meio de usos indiferenciados, condizentes com as propriedades físicas dos artefatos. Assim, elas manipulam, mordem e chupam objetos até que, superada a tensão entre o canônico e o não canônico, adentram nas regras da cultura e passam a utilizá-los simbolicamente (Palacios, \& Rodríguez, 2015).

A estabilização momentânea na sequência das ações da criança permite identificar o jogo polifônico subjacente aos usos simbólicos dos objetos entre os discursos dominantes situados nas práticas familiares e nos valores sociais. As múltiplas vozes se atualizam e, em sua variedade de manifestações (verbais, corporais ou na forma de expectativas), atuam na regulação dos significados na intersubjetividade.

O enfoque no uso de artefatos possibilita a observação sobre como os espaços de atualizações de significados são utilizados para reafirmar o convencional na cultura. Na infância, eles são produzidos na forma de brinquedos, que apresentam elementos semântico-ideológicos (os significados e as expectativas culturais preferenciais).

O uso que se faz dos brinquedos aponta para caminhos de mediação simbólica que "não estão fundamentados em uma realidade 'a priori', mas em regras compartilhadas de usos sobre os objetos" (Palacios, \& Rodríguez, 2015, p. 23). Assim, no processo de socialização, a criança entrará em contato com os usos canônicos e convencionais dos objetos da cultura, que estabelecerão suas possibilidades de significação (Bruner, 1997).

Ao brincar, a criança lida com normas e expectativas sociais que desconhece. Sua versão de uso em brincadeiras é muitas vezes tida como subversiva, pois se assenta em uma capacidade criativa que ainda não conhece a rigidez da esfera convencional de nossa cultura. A articulação entre esferas convencionais e não convencionais não enrijece posicionamentos, incentivando a criatividade e agencialidade da criança.

\section{Significados de gênero na infância}

Os significados de gênero têm sido produzidos mediante sistema de signos e artefatos culturais, em condições históricas de fabricação em dispositivos de poder (Foucault, 2012). As práticas cotidianas refletem o caráter diluído das relações de poder, que podem ser observadas pela maneira como valores e significados são produzidos. Estes, em si, não apresentam valência positiva ou negativa, pois são agenciados dialógica e coletivamente, na relação entre sujeitos, exercendo impacto no controle dos corpos, da sexualidade e da produção de subjetividades. 
O sistema sexo-gênero, como aparato semiótico-cultural das sociedades, transformou a sexualidade humana num produto de sua atividade social (Rubin, 1997); o "sexo" passou a ser matéria-prima que mantém intacta a diferença sexual. Por muito tempo, as definições biológicas, sociais ou culturais tenderam a tomar o gênero ou a sexualidade como categorias estanques, pois foram produzidas por determinados regimes de saber-poder normalizadores (Foucault, 1988) ou "convencionalizadores", para utilizar o termo que adotamos neste texto.

Assim, a categoria de sexo, pautada pelo discurso da biologia, diz que há um conjunto de elementos anatômicos e fisiológicos que distinguem homens de mulheres e configura-se como dado a-histórico. Já a categoria de gênero está estreitamente ligada a uma produção social e histórica e à forma de como as práticas de subjetivação se definem (Arán, 2006).

Essas formulações permitem a Butler pensar acerca dos regimes de poder reguladores das normas de gênero (Butler, 2013), sendo possível afirmar que as práticas de constituição do sujeito são engendradas por normas regulatórias de gênero. A autora realiza um debate sobre como a categoria de gênero foi sendo compreendida pela teoria feminista contemporânea, em que a noção de gênero passa a ser entendida como uma interpretação cultural do sexo. O problema dessa perspectiva é vê-lo a partir de um determinismo social que exclui a possibilidade de agência e transformação (Butler, 2013). Isto é, além de uma esfera estritamente convencional.

A categoria de sexo e de gênero nem sempre se constituiu da mesma maneira em diferentes períodos históricos (Butler, 2013). Enquanto Foucault (1988) usa o termo sexo ao conduzir a história da sexualidade, o que chama de sexo-rei devido ao seu caráter altamente produtivo e regulatório, Butler prefere usar o termo gênero para falar de algo semelhante. Assim, a autora desfaz a distinção que separa as noções de sexo e gênero para defender a tese de que não há sexo que não seja já e, desde sempre, gênero. Em outras palavras, a categoria sexo faz parte de uma demarcação discursiva apoiada em práticas sociais convencionalizadas. Não existe possibilidade de existência humana que não seja social, o que significa que não existe corpo natural (o sexo biológico) preexistente à sua inscrição cultural.

Ao visualizar os modos como os significados de gênero são produzidos na infância, observamos a existência de elementos culturais que funcionam como lugares privilegiados dessa produção, como o mencionado aparato semiótico relacionado ao sistema sexo-gênero (Rubin, 1997). Tal sistema, por sua vez, potencializa relações específicas entre as práticas familiares e as práticas culturais que circulam na comunidade em que a criança se desenvolve, visando agenciar papéis sociais para fabricar um menino "masculino" e uma menina "feminina". Esse momento se organiza em suas particularidades e condições devido à perspectiva binária de gênero que ocupa posição canônica nas atualizações dos discursos.

Desse modo, as brincadeiras funcionam como tecnologias de gênero (Lauretis, 1987), visto que regulam práticas mediante demarcações binárias em lugares sociais e, assim, meninas e meninos passam a ocupar posições diferenciadas em nossa cultura quando se tornam adultos. Em nossa tradição ocidental, brinquedos e cores são utilizados como dispositivos que atuam a serviço do binarismo das normas de gênero (Cruz, Silva, \& Sousa, 2012), podendo incluir ou excluir crianças de determinadas brincadeiras. Recursos midiáticos, tais como desenhos e filmes de animações, também são tecnologias poderosas na produção de significados de gênero (Monteiro, \& Zanello, 2015).

Os significados de gênero podem assumir sua versão convencional (ou não convencional) na forma como são representados pela nossa cultura e as brincadeiras podem reproduzir ou subverter relações tipicamente "gendradas" (Lauretis, 1987). No contexto lúdico, tal prerrogativa é capaz de questionar todo uso dos brinquedos, problematizando os significados que estes assumem, sob a argumentação de serem produções culturais que se atualizam a cada interação e apresentam potencial para uso além do convencional.

No intento de propor arranjos que avancem no estudo da produção de significados de gênero na primeira infância, o presente estudo foi realizado conforme o paradigma processual em metodologia qualitativa, com a combinação de vários procedimentos, e teve como unidades de análise a interação de crianças em brincadeiras e discursos orais. Segundo Barbato et al. (2016), a combinação de estratégias de pesquisa e métodos acrescenta rigor e profundidade na compreensão dos resultados, além de aprimorar o desenvolvimento de perspectivas epistemológicas em Psicologia. 


\section{Método}

\section{Procedimentos, contexto e instrumentos}

O Comitê de Ética em Pesquisa do Instituto de Ciências Humanas da Universidade de Brasília aprovou o projeto em que se insere o estudo relatado neste artigo no parecer $n^{\circ} 742.952$ de 31/07/2014. Cuidadores e cuidadoras foram convidados/as a participar da pesquisa. $\mathrm{O}$ único critério para participação era que as crianças tivessem no máximo três anos de idade. Selecionadas por conveniência, Rosana, Patrícia, Marcela e Ana ${ }^{1}$, todas mulheres cuidadoras de meninas, aceitaram o convite.

Os dados foram produzidos no contexto urbano de uma capital do país, na residência das participantes, e as cuidadoras foram as responsáveis por indicar o cômodo mais silencioso e apropriado, levando em consideração a privacidade e a segurança da criança. Os brinquedos utilizados durante as sessões de interação foram escolhidos com base em sua associação estereotipada aos gêneros feminino e masculino ${ }^{2}$, de acordo com as práticas do local $^{3}$. De acordo com a classificação binária de gênero construída pelo pesquisador, dois recipientes foram padronizados - o com imagens de princesas correspondeu ao estereótipo feminino e outro com imagem de carros, ao masculino - e estavam disponíveis no ambiente.

Os procedimentos foram realizados em quatro etapas, com duração total de 10 minutos cada: (I) observação da interação diádica (criança-brinquedo), em que brincaram livremente sozinhas interagindo com os brinquedos; (II) interação triádica (pesquisador-criança-brinquedo), em que classificaram como "de menino", "de menina" e "dos dois" e guardaram os brinquedos nos potes "de princesa" ou "de carros"; (III) observação da interação triádica (cuidadora-criança-brinquedo), em que, com os mesmos objetos, cuidadora e criança foram instruídas a brincarem livremente. Um responsável esteve presente em espaço adjacente, acompanhando as etapas I e II. Posteriormente, foi realizada escuta das cuidadoras, por meio de entrevista temática (etapa IV), em que foram trabalhados temas relacionados às brincadeiras, aos brinquedos e à história da criança e de sua família. Todas as sessões foram videogravadas com consentimento das crianças e assinatura do TCLE (Termo de Consentimento Livre e Esclarecido) pelas responsáveis.

Os dados foram transcritos e as ações realizadas por cada uma das crianças foram categorizadas em brincadeiras, considerando-se três aspectos: (a) os brinquedos que foram utilizados; (b) os usos destes brinquedos (isto é, convencional ou não convencional); e (c) os significados atribuídos a estes usos, a partir de uma sequência de atividades. As interações com o pesquisador e as cuidadoras foram submetidas à análise dialógica temática (Barbato et al., 2016), o que possibilitou a identificação dos significados produzidos. Por fim, analisamos como as práticas culturais e as polifonias estão presentes na convencionalização de significados de gênero em brincadeiras.

\section{Participantes}

Rosana, de 20 anos, é divorciada e mãe de Melissa, de três anos, sua única filha. Trabalha como recepcionista em um hospital e conta apenas com a ajuda dos pais (em especial sua mãe), para cuidar da filha, que já frequenta uma creche em período parcial. Em entrevista inicial, Rosana conta que costuma brincar com a filha sempre que chega do trabalho, mas que esta passa mais tempo com a avó, que é dona de casa. Sobre as brincadeiras, remete-se às que brincava com os próprios pais durante sua infância, como de "bicho papão", esconde-esconde, brincadeiras de rua e boneca. Afirma que sua filha gosta de imitá-la em "coisas de vaidade" e que elas fazem brincadeiras em atividades de se arrumar, como escolher a roupa, passar maquiagem, pentear o cabelo etc. Os brinquedos tecnológicos e educativos também estão entre os preferidos e não há restrições a qualquer outro tipo de brincadeira, pois considera que em cada uma há um aprendizado. Lembra-se de episódios em que sua filha brincou de futebol com a avó e não acredita haver brincadeiras diferenciadas por gênero.

Patrícia, de 42 anos, é casada e mãe de Catarina, de dois anos e meio, sua única filha. Trabalha como costureira em sua própria casa. Embora algumas atividades sejam de sua responsabilidade exclusiva, como

\footnotetext{
${ }^{1}$ Os nomes das cuidadoras e das crianças são fictícios.

${ }^{2}$ Relacionados ao gênero feminino, foram utilizados dois bebês, fogão, panelas e utensílios domésticos e, ao masculino, dois aviões, dois carros, moto, espada, ferramentas e skate.

${ }^{3}$ Eles foram classificados com base em um estudo exploratório feito previamente em shoppings, no qual foi solicitado a 48 crianças de mesma faixa etária das que participaram do estudo que avaliassem fotos de brinquedos similares aos utilizados e os julgassem como "de menina", "de menino" ou "dos dois".
} 
dar banho na filha e os serviços domésticos em geral, outros cuidados são divididos com o marido, aposentado, em especial a parte lúdica. Lembra-se das tarefas bem divididas por gênero em sua própria criação e das brincadeiras "de seu tempo", como bonecas feitas de sabugo de milho e brincadeiras de roda. Afirma que as tecnologias (como computador e celular) a incomodam e prefere os brinquedos "de sua época" por considerá-los mais adequados a crianças menores. Patrícia diz que os brinquedos devem ser diferenciados por gênero e que este é um aspecto que ela leva em consideração na hora de escolher com o que a filha irá brincar.

Marcela, de 20 anos, é solteira e irmã de Olívia, de três anos. Além da caçula, Marcela tem outros dois irmãos, de 21 e 18 anos. Marcela e Olívia não moram juntas, mas convivem quase diariamente, pois é na casa que ela mora (junto também ao pai, à avó paterna, uma tia e dois primos) que Olívia fica enquanto não está na creche (a mãe e o pai de Olívia trabalham durante todo o dia). Marcela apenas dedica-se à faculdade. As tarefas domésticas eram divididas com os irmãos e demais parentes da casa e o cuidado com Olívia, compartilhado com a avó, que é dona de casa. Marcela comenta sobre certa tendência das crianças atuais preferirem brinquedos tecnológicos, como computador, tablets e celulares e lembra que, em sua época de infância, eram mais comuns brincadeiras de boneca, casinha e de rua, com as quais brinca com Olívia como forma de ensiná-la a diversificar as brincadeiras. Afirma que existem brinquedos diferenciados por gênero e que um dos principais critérios para a diferenciação é a cor rosa, exclusivamente feminina.

Ana, de 22 anos, é casada, mãe de Mirela, de três anos, e está grávida da segunda filha. Mirela participou apenas das etapas 1 e 2, devido à impossibilidade de Ana (sua mãe, que havia aceitado previamente participar do estudo) ou outro/a cuidador/a comparecer às outras etapas, que incluía a entrevista que permitiria maiores informações sobre a dinâmica familiar e as vivências relacionadas às brincadeiras e brinquedos.

\section{Resultados e discussão}

Os resultados indicam como os processos de convencionalização ocorrem nas interações orientados para a manutenção do binarismo como dinâmica dominante na produção de subjetividades, atribuindo ao/à cuidador/a a regulação destes significados.

Destacamos no primeiro momento os resultados relacionados aos processos de convencionalização de significados das etapas iniciais do estudo e, então, apresentamos, como exemplificação, episódios de falas das mães em entrevista e momentos de interação para discutir como as polifonias atuaram orientando a regulação e atualização de significados.

\section{Etapa I}

Na primeira etapa do estudo, as crianças interagiram sozinhas com os brinquedos. A análise dos usos que elas fizeram destes artefatos apontou para duas categorias de brincadeiras comuns: (a) cuidar da aparência (seja da boneca, de si ou dos outros) e (b) comidinha. Outra brincadeira, identificada apenas na interação de Mirela com os brinquedos, foi a que chamamos de "consertar", onde ela fez uso de ferramentas (furadeira, martelo, parafusos etc.) para produzir uma situação de trabalho. O Quadro traz informações sobre os brinquedos utilizados e os tipos de uso (isto é, convencional ou não convencional).

Nesta etapa, consideramos o modo pelo qual a criança interagiu com artefatos culturais (os brinquedos). No processo de naturalização de usos convencionais, existe um jogo simbólico entre estabilização e flexibilização, como é possível visualizar na substituição de um objeto por outro (Palácios, \& Rodríguez, 2015), na mescla de usos convencionais e não convencionais dos brinquedos. Na interação de Melissa,

\section{Quadro}

Brincadeiras realizadas durante a etapa I do estudo.

\begin{tabular}{|c|c|c|}
\hline \multicolumn{3}{|c|}{ Brinquedos e Usos } \\
\hline & Convencional & Não Convencional* \\
\hline $\begin{array}{l}\text { Cuidar da } \\
\text { aparência }\end{array}$ & $\begin{array}{l}\text { Chapinha, } \\
\text { boneca, escova } \\
\text { de cabelo }\end{array}$ & $\begin{array}{l}\text { Chave de fenda } \\
\text { (escova de dente) e } \\
\text { chapinha (ferro de } \\
\text { passar roupa). }\end{array}$ \\
\hline Comidinha & $\begin{array}{l}\text { Colher, panela, } \\
\text { prato e fogão }\end{array}$ & $\begin{array}{c}\text { Depósito de } \\
\text { ferramentas (pia), } \\
\text { furadeira (torneira), } \\
\text { chave de fenda } \\
\text { (colher), moto e } \\
\text { secador de cabelo } \\
\text { (ingredientes). }\end{array}$ \\
\hline $\begin{array}{l}\text { Consertar } \\
\text { (apenas } \\
\text { Mirela) }\end{array}$ & $\begin{array}{c}\text { Furadeira, } \\
\text { martelo, } \\
\text { parafuso }\end{array}$ & - \\
\hline
\end{tabular}

*As palavras entre parênteses na coluna "não convencional" se referem aos usos realizados pela criança. 
por exemplo, a atribuição de significados não convencionais aos brinquedos se expressa quando ela segura o recipiente onde as ferramentas estão depositadas e diz "vou lavar a louça", ação esta que é seguida de outros movimentos que confirmam o novo significado atribuído ao objeto: o de pia. Em outro momento, ela segura uma ferramenta (chave de fenda), direciona à boca e, em seguida, faz movimentos de escovação dos dentes. Neste caso, o novo significado atribuído ao brinquedo foi o de escova de dentes.

A convencionalização em brincadeiras ocorre em, pelo menos, dois níveis: (a) na esfera dos usos simbólicos de objetos em práticas culturais e (b) em direção às expectativas culturais relacionadas às categorias identitárias. Embora ambos níveis se refiram a processos que têm como objetivo um mesmo fim (chegar-se ao convencional), observamos que dinâmicas bem diferentes acontecem. O primeiro nível é o que ocorre em direção à assimilação do uso culturalmente "correto" do brinquedo, que diz respeito aos significados públicos e normativos dos objetos, com base em sua função (Palácios, \& Rodríguez, 2015). Assim, a criança faz uso não convencional quando utiliza a ferramenta como se fosse escova de dentes, direcionando o brinquedo aos dentes e à língua, realizando movimentos de escovação ${ }^{4}$ e convencional quando utiliza uma panela para cozinhar (já que, em nossa cultura, utilizamos panelas para cozinhar). Este fenômeno indica que ela está em processo de produção de semioses próprias em negociação com a esfera de significados coletivos. A criança mostra quais regras sobre uso convencional de objetos ela já aprendeu. No caso citado, o uso de objetos em contexto de alimentação.

O segundo nível é o que se dá em direção às expectativas culturais relacionadas às categorias identitárias, sempre permeadas por relações de poder. No caso da produção de significados de gênero, é explícita a convencionalização quando as meninas fazem brincadeiras que estão em consonância ao que se espera socialmente de uma garota feminina. O significado de gênero atualizado nas brincadeiras chamadas de "cuidar da aparência" e "comidinha" parece ser o relativo à produção de uma identidade feminina, observável em estudos do século passado como ocorrendo antes do terceiro ano de vida (Cowan, \& Hoffman, 1986; Robinson, \& Morris, 1986; Sprung, 1983). Há uma compreensão ainda cristalizada, compartilhada e transmitida às crianças, de que às meninas cabe estar nos espaços relativos ao cuidado, compreendendo o âmbito das tarefas domésticas e o espaço privado de preocupação com a beleza, a vaidade e a atenção dedicada aos outros. Cabe lembrar que a situação concreta de vida das crianças do estudo é marcada por figuras femininas na posição principal de cuidado em relação a elas, à casa e aos demais membros da família. Isto é atualizado nas brincadeiras e funciona como tecnologia de gênero (Lauretis, 1987), pois demarca lugares sociais e produz determinados caminhos de subjetivação.

A esfera não convencional, tomando-se como base o ainda (não) comum em nossa cultura, é perceptível, neste nível, quando Mirela utiliza as ferramentas (furadeira, martelo e chaves de fenda) para brincar de "consertar", ocupando simbolicamente um espaço que, segundo o estereótipo, vai em direção contrária aos ideais de feminilidade e introduz novidades na lógica convencional. Dada a impossibilidade de entrevistar um/a cuidador/a de Mirela, não há como analisar a fundo de que forma esta brincadeira não estereotipada se inscreve na vida desta criança, em oposição às brincadeiras realizadas pelas outras crianças, que reforçam elementos da vivência cotidiana e da expectativa social de que o cuidado e a preocupação com a imagem são funções femininas.

É interessante perceber que há uma reprodução da lógica do primeiro nível para o segundo, sem que as diferenças existentes sejam postas em discussão. Quando se trata da apreensão do uso "adequado" de determinado objeto cultural, falamos da produção de uma semiótica baseada em propriedades materiais que foram convencionalizadas no decorrer da história da humanidade para servirem a determinados fins (por exemplo, uma faca para cortar, um carro para servir como meio de transporte, uma chapinha para passar nos cabelos). Neste caso, o esforço cultural rumo à convencionalização está em transmitir um legado histórico acumulado. Quando se aplica o mesmo princípio em relação às categorias "identidades de gênero", o que se percebe é a tentativa de que o sexo biológico sirva como propriedade material naturalizada para justificar o binarismo enquanto cânone. Além disso, a tentativa de manutenção de determinados lugares de poder, pela demarcação de lugares sociais diferenciados entre homens e mulheres, além

${ }^{4} \mathrm{O}$ uso não convencional que a criança fez foi de utilizar uma ferramenta (chave de fenda) como escova de dentes, fazendo movimentos de escovação. Trata-se de um uso não convencional, já que não costumamos utilizar uma chave de fendas para escovar os dentes. 
de tornar invisíveis os indivíduos que não se encaixam em concepções binárias de gênero.

A substituição de um objeto pelo outro evoca a polifonia, ou seja, significados relacionados a objetos e situações que indicam histórias de interações que as crianças já tiveram ao longo de suas vidas. No caso de Melissa, por exemplo, o ato de utilizar uma ferramenta para escovar os dentes pode indicar interações já vivenciadas por ela, relacionadas a este ritual, que foram atualizadas na brincadeira.

\section{Etapa II}

Na segunda etapa do estudo, o pesquisador interagiu com cada criança e propôs uma classificação binária dos brinquedos. Este procedimento teve como objetivo identificar quais seriam as estratégias utilizadas por elas para classificar os objetos, o que, provavelmente, indicaria como elas significavam suas ações nas brincadeiras em relação ao gênero.

As duas principais perguntas feitas às crianças foram: (a) quem poderia brincar com cada brinquedo (menino, menina ou os dois) e (b) em qual recipiente (de princesas ou de carros) cada brinquedo deveria ser guardado. Foram identificados dois tipos principais de classificações utilizadas: (I) estereotipada, quando a criança faz uso de estereótipos de gênero como critério para guardar os brinquedos (por exemplo, quando utiliza informações sobre cores); e (II) ambivalente, quando: (a) as crianças enunciam a periculosidade de brinquedos, como espada, serrote e faca (que cortam), enunciando que ninguém pode brincar com eles e depois afirmam que são brinquedos de menino (Olívia, Melissa, Catarina); b) há enunciação de que o brinquedo é dos dois gêneros (Melissa); c) há dois exemplares do mesmo objeto e são guardados um em cada pote (Melissa); d) o de carros é dito como "de homem" e o de princesas como "de mulher", mas os brinquedos que são colocados nos dois são "de mulher" (Melissa) ou são colocados os brinquedos classificados como "de menino" na caixa nomeada "princesas" (Olívia, Mirela e Catarina).

Os resultados desta etapa indicam que ambivalências (Abbey, \& Valsiner, 2005) e tensões permeiam as produções de significados nas explicações de si, do outro e do mundo nas brincadeiras. Quando confrontadas a explicar quem pode brincar com os brinquedos, onde eles devem ser guardados e por que, observamos que as crianças negociam com a cultura, em direção à convencionalização descrita anteriormente como do segundo nível, relacionada às categorias identitárias, e, além disso, as crianças introduzem novidades, produzindo ambivalências que podem indicar, por sua vez, mudanças culturais em andamento. Ao categorizar os brinquedos e escolher quem pode brincar com eles, a criança utiliza informações sobre gênero que já dispõe e é orientada à identificação com um dos dois gêneros, em processos que, conforme Fausto-Stearling (2012), não são vistos pelas crianças como tão permanentes assim.

A ambivalência na classificação dos brinquedos, forçada pelo pesquisador, enuncia o jogo de permanência e mudança na produção de significados. $\mathrm{Na}$ interação com Melissa, por exemplo, a ambivalência se expressa logo no início, no momento em que o pesquisador pergunta com quais brinquedos ela mais havia gostado de brincar.

- Melissa, com qual brinquedo você mais gostou de brincar? Me mostra aí.

- Esse, esse, esse, esse, esse... [apontando para todos os brinquedos]

- Com qual você não brincou?

- Eu brinquei de tudo!

- Até com esse aqui? [segurando a espada]

- Não. Esse é mau, menina não pode.

- Por que menina não pode brincar?

- Porque ninguém pode brincar.

- Ninguém? Nem menino?

- Menino pode! (Pesquisador e Melissa, 3 anos)

No caso acima, a criança se mostra inicialmente aberta a todos os brinquedos, até que, quando confrontada pelo pesquisador, faz uso de seus conhecimentos e de sua experiência para produzir significados diferentes, como o de que a faca é perigosa porque corta e, que, portanto, ninguém pode brincar com ela. Tal opinião novamente muda, quando ela postula que um menino pode brincar com a espada. Em toda a interação, observamos como a produção de significados se dá de forma ambivalente, entre regras e suas subversões. A entrevista com sua mãe, Rosana, evidenciou que Melissa sempre teve liberdade para brincar com todos os brinquedos, independente de restrições impostas por ela em relação às categorias de gênero. Em outros momentos da interação com esta criança, observamos que a regulação dos significados se dá muito mais no sentido de abertura à situação de brincadeira do que em direção a posicionamentos rígidos relacionados ao gênero. 
Melissa afirma ter brincado com aviões, caminhões e carrinhos (que, de fato, não brincou), o que expressa uma atitude de abertura, em oposição a uma espontânea ou "natural" recusa. Quando o pesquisador pergunta quais brinquedos ela acha que são de menino, é surpreendido com a resposta "Acho que eu não acho. Só menina que pode brincar". Quando perguntada sobre quais brinquedos meninos e meninas podem brincar, ela é enfática ao responder: “Tudo!". O pesquisador também pergunta quem pode brincar com o caminhão e ela responde "Eu. Só eu". Pergunta se menino pode brincar com a chapinha e ela responde que "Não. É chapinha.... É rosa". Pergunta se dentro do recipiente "de carros" devem ser colocados brinquedos "de menino", "de menina" ou "dos dois" e ela responde "de homem". Faz a mesma pergunta relacionada ao recipiente de "princesas" e ela responde "de mulher". Em seguida, pergunta quais brinquedos vêm no depósito de carros e ela responde "de mulher". A mesma pergunta é realizada, referente ao pote "de princesas" e ela responde "de mulher". O pesquisador pergunta por que os dois são de mulher e ela responde "Porque sim. Porque eu quero brincar".

De fato, a última resposta de Melissa parece sintetizar bem o que uma criança espera de um momento lúdico: o brincar e o faz de conta, como forma de comportar a mudança de objetos, orientando-os para a inclusão de si. Observamos que há estratégias de classificação estereotipadas, quando ela afirma que menino não pode brincar com a chapinha porque ela é rosa, e, em sua maioria, ambivalentes, quando a criança tenta negociar os novos significados com sua experiência e significados culturais já convencionalizados, bem como a expectativa que tem em relação ao outro, no caso, sobre o pesquisador deixá-la brincar.

Para Catarina, a própria dinâmica de perguntar sobre quem pode brincar com os brinquedos e de guardá-los em recipientes estereotipados é vista como uma brincadeira. A criança mostra-se contente cada vez que demonstra conhecer o objeto, para que serve e quem "pode" brincar com ele. Grande parte de sua classificação segue curso estereotipado, demonstrando que ela, mesmo sendo a mais jovem (apenas dois anos e seis meses), apresenta conhecimento das normas culturais relacionadas ao gênero.

Ainda assim, a classificação ambivalente surge em alguns momentos, como quando coloca um avião e um caminhão no pote "de princesas", classificado como "de menina", mesmo tendo dito anteriormente que tais brinquedos eram de menino. Também há ambivalên- cia quando afirma que a chapinha pode ser brincada por meninos e meninas, mas decide colocá-la no pote de princesas, classificado como "de menina". Por fim, quando perguntada sobre qual caixa de brinquedos ela gostaria de brincar, se pudesse levar para casa, Catarina responde que as duas, resposta esta que também parece sintetizar bem o que se espera de um momento lúdico: brinquedos com os quais possa brincar.

A entrevista com Patrícia, mãe de Catarina, trouxe elementos interessantes para pensar como a polifonia (Volosinov, 2009) teria atuado na regulação da produção de significados nesta interação. Patrícia afirmou que há brinquedos que são típicos de meninos e/ou de meninas e este é um aspecto importante na hora de escolher as brincadeiras das crianças. Comentou que Catarina, inclusive, havia lhe pedido um carrinho e que sua resposta tinha sido "Não, minha filha, carrinho é coisa de menino, você brinca de boneca". Quando questionada sobre o que poderia significar uma menina brincar com um carrinho, ela afirmou que não achava que significasse coisa alguma, mas que existe preconceito das pessoas, decorrente do fato de que possam interpretar esta ação como um sinal de homossexualidade. A preocupação expressa pela mãe revela uma compreensão derivada do senso comum de que a concepção de gênero equivale à noção de sexo e de sexualidade (Butler, 1993;2013), pois brincar com objetos ditos de outro gênero poderia fazer de sua filha uma criança masculina e não homossexual. Dessa forma, o que está em questão para a mãe da criança não é a identidade de gênero, mas sim a orientação sexual e todas as repercussões relativas ao papel da heteronormatividade e do binarismo como dinâmicas de regulação sociais dominantes.

A voz do cuidador se constitui como uma das vozes na polifonia, que atua na regulação dos significados de gênero, mesmo em brincadeiras individuais. As escolhas de Catarina indicam conhecimento sobre significados convencionais de gênero, o que permite pensar sobre outros dispositivos com os quais ela já teria entrado em contato na produção destes significados, entre eles a expectativa do/a cuidador/a.

$\mathrm{Na}$ interação de Olívia com o pesquisador também foi possível observar atualizações de significados de gênero bem consolidadas e alinhadas ao estereótipo binário de gênero. Outros exemplos sobre uso não convencional do primeiro nível estiveram presentes, relacionados ao uso culturalmente "correto" do brinquedo. $\mathrm{O}$ modo como a criança faz usos não 
convencionais de brinquedos quando o objeto é tradicionalmente relacionado a certos fazeres/atividades pode indicar produção inicial ou internalizada de atividades relacionadas tradicionalmente às meninas como cuidar, cozinhar, lavar, passar etc. $\mathrm{O}$ trecho abaixo exemplifica este processo.

- O que você mais gostou de brincar, Olívia? Com qual brinquedo?

- Brinquei com esse aqui e brinquei com esse aqui [segurando o secador e a chapinha]

-E esse aqui serve pra quê? [com a chapinha da mão]

- Pra passar roupa!

- Passar roupa? Como é que passa roupa com ele? Me mostra [Olívia pega a chapinha e leva até sua própria roupa] (Pesquisador e Olívia, 3 anos).

A entrevista com Marcela, irmã de Olívia, também permite pensar aspectos relacionados à voz dos cuidadores/as nas polifonias que regulam as atualizações de significados. Marcela afirma que costuma brincar de "comidinha" com a irmã (tal como observado na brincadeira que Olívia faz sozinha) e que, em sua opinião, as brincadeiras relacionadas à casa, como comidinha e bonecas (o que remete ao cuidado materno), são mais da menina. Diz ainda que menino gosta mais de violência, de carrinho, de corrida. Afirmou que Olívia tem um carrinho de controle remoto de menina, cuja diferença em relação aos de menino é a cor (rosa). Concorda que existem brinquedos diferentes para meninos e meninas e que sua posição é a de incentivar que Olívia brinque com brinquedos ligados ao seu gênero.

Observamos, portanto, como são instauradas práticas discursivas próprias para o gênero feminino por meio de brinquedos. O carrinho de controle remoto, brinquedo tipicamente masculino, precisa se tornar feminino para que a criança possa brincar. É interessante a discussão proposta por Cruz et al. (2012) de que brinquedos femininos, em contrapartida, ainda não passaram por processos de masculinização, o que reflete, em contexto lúdico, as mesmas tensões que embalam a produção da masculinidade, que se constitui na afirmação de uma negação da feminilidade, em que é posto em evidência o fato de que ser homem é não ser doce, afeminado, entre outros. (Zanello, \& Gomes, 2011).

Mirela, que havia brincado de "consertar" na etapa de brincadeira individual, afirma ao pesquisador ter brincado com todos os brinquedos, mesmo que só tenha brincado com as ferramentas. No momento da classifi- cação, utiliza-se, na maior parte do tempo de estratégias estereotipadas de categorização. Os atos ambivalentes de classificar surgem quando, mesmo distribuindo determinados brinquedos como "de menino" (moto e algumas ferramentas), opta por guardá-los no pote "de princesas", nomeado como "de menina".

Percebemos nesta etapa que os significados vão sendo dialogicamente produzidos de maneira que, à primeira vista, parecem contraditórios. Pensamos, porém, que a dinâmica dialógica da produção de significados (não centrada na concepção de uma identidade estanque, mas regulada por jogos polifônicos) permite que observemos os fenômenos a partir de outro olhar: 0 que toma a contradição como possibilidade de se pensar as diferenças situadas nas relações sociolinguísticas.

\section{Etapa III}

Na etapa final, em que a criança interagiu com a cuidadora, os resultados indicam que: (a) as brincadeiras são relacionadas a atividades tradicionalmente femininas indicadas por ações de guardar, organizar e cuidar; (b) a presença das mesmas brincadeiras da primeira etapa do estudo (cuidar da aparência e comidinha), com o acréscimo de duas novas brincadeiras. A primeira, surgida no diálogo entre Marcela e Olívia, consistia no jogo “inversão de papéis", em que a criança era a mãe e a mãe a criança. A segunda, no contato entre Catarina e Patrícia, sugere que guardar os brinquedos nos recipientes estereotipados foi interpretado como atividade lúdica.

A observação de como todas as crianças interagiram com as cuidadoras indica a vozes das cuidadoras como uma constante na dinâmica polifônica. A repetição das brincadeiras da primeira etapa, quando brincaram sozinhas, na terceira etapa, quando brincaram com a cuidadora, pode indicar que poderia ter havido maior variedade de brinquedos e que aquelas brincadeiras são parte das práticas culturais que ocorrem em seus cotidianos e nelas há atualizações de atuações e significados. A expectativa da cuidadora constitui importante voz na polifonia, uma vez que, na intersubjetividade, elas se posicionaram movimentando e substituindo objetos utilizados pela criança por outros ou enunciando e organizando a sequência das atividades por meio de instruções e perguntas. Houve alguns momentos em que as brincadeiras envolviam menos assimetrias cuidadora-criança, em que foi observado que as cuidadoras seguiam as atividades das crianças, simplesmente brincando ou observando. A potencialidade de canalização ou não 
das atuações das cuidadoras são enfatizadas, considerando-se a sua importância afetiva para a criança. Esta relação, portanto, constitui espaço privilegiado na convencionalização, bem como na possibilidade de subversão de significados de gênero, quando as expectativas do/a cuidador/a não estão pautadas em uma lógica estritamente convencional.

Um aspecto interessante que influi na importância conferida aos/às cuidadores/as na convencionalização de significados consiste na redução quase total de usos não convencionais dos brinquedos pelas crianças, explicada pela mediação estabelecida, no sentido de indicar o uso convencional, segundo as expectativas culturais, tanto relacionadas ao uso tradicional interpretado como "correto", quanto às identidades de gênero; isto é, a quem pode brincar com qual brinquedo. No episódio a seguir, retirado das transcrições da interação entre Olívia e sua cuidadora Marcela, é possível visualizar como ocorre a mediação no sentido de produção do conhecimento e do direcionamento da ação de um sentido não convencional para o convencional:

- Isso aqui é de quê? [Marcela passa a chapinha nos cabelos]

- Passar a roupa.

- Uhm, uhm... [Olívia balança negativamente a cabeça]

- É sim. Passar chapinha.... Assim ó. [Passa no cabelo de Olívia] Viu? Esse aqui também, ó... [segurando o secador]

- Fica com isso aqui. [Olívia entrega a espada para Marcela]

- Isso aqui é de menino, ó... [Marcela faz movimentos de espada]

- Para! (Marcela, irmã, 20 anos, e Olívia, 3 anos)

Como observado na etapa de interação com o pesquisador, Olívia utilizava a chapinha como ferro de passar roupa, significado este que foi atualizado na interação com a cuidadora. Um significado de gênero também é produzido quando Marcela afirma que a espada é um brinquedo de menino. Outro aspecto relevante desta interação é o surgimento da brincadeira "inversão de papéis", dito na entrevista de Marcela como brincadeira comum entre elas. Este tipo de interação põe em evidência as outras vozes da polifonia, cujos significados atualizados falam de toda uma história de interações ocorridas na vida da criança. Olívia faz uso de um conjunto de elementos que já esteve em contato durante a vida (relações com os próprios pais, outras brincadeiras realizadas com Marcela) para a construção de sua brincadeira, como explicitado no episódio abaixo:

- Não, filha! Não, filha! [Impedindo Marcela de levar o pente ao cabelo]

- Eu sou a mamãe e você é a filhinha.

- Não, eu sou a mãe e você é a filha.

- Não, eu sou a mamãe.

- Não vou ser sua filha. [Olívia se levanta, vai até a parede e cruza os braços]

- Você não quer? Então tá bom. Você é a mamãe.

Eu sou a filhinha (Marcela, irmã, 20 anos, e Olívia, 3 anos)

Na interação entre Catarina e Patrícia, a própria criança pede à mãe que elas brinquem de guardar os brinquedos nos recipientes estereotipados, o que sugere que o próprio contexto da pesquisa, especialmente a interação com o pesquisador, constituiu espaço para a produção de significados de gênero. A brincadeira seguiu de forma que todos os brinquedos foram guardados segundo a classificação estereotipada de gênero, enquanto na interação com o pesquisador foi possível observar algumas classificações do tipo ambivalente.

Na interação entre Rosana e Melissa ocorrem atualizações de algumas brincadeiras realizadas individualmente pela criança, como é o caso da brincadeira "comidinha”, proposta pela cuidadora, mesmo ela não tendo acompanhado a primeira etapa. O diferencial desta sessão é que, em oposição às etapas anteriores, marcadas por alguns usos não convencionais de brinquedos e classificações ambivalentes, o que, inclusive, conferia certo tom "criativo" às brincadeiras, a interação ocorre inteiramente regulada por significados convencionais. A mediação se dá quando a mãe envolve a criança e pede sua colaboração, momentos estes em que se produz conhecimento, atravessado por questões de gênero:

Vamos fazer comida? Cadê o fogão?

Bora. Vamos fazer a comida! [A criança pega o fogão e coloca ao lado da cuidadora]

O que você vai fazer de comida?

Arroz, carninha... Arroz! Feijão!

Então pega uma panela aí pra gente fazer. [A criança pega uma panela e põe perto do fogão] 
Me dá uma colher. [A criança pega uma colher e entrega à cuidadora] (Rosana, 20 anos, mãe, e Melissa, 3 anos).

Observamos nesta etapa que, no espaço intersubjetivo cuidadora-criança, as interlocutoras produzem tanto o convencional quanto as ambivalências de fazeres. Tanto adultos quanto crianças posicionam-se entre o convencional e o não convencional, nas fronteiras entre permanências e mudanças. Tais fronteiras ganham contorno quando as interlocutoras brincam convencionalmente e a criança atua não convencionalmente, quando ocorre certo direcionamento de sua atuação para o convencional, quando a cuidadora direciona os movimentos da criança, organizando seu corpo, seus movimentos e espaços.

\section{Considerações finais}

A convencionalização ocorre nas negociações de significados e atuações na intersubjetividade, no jogo entre permanências e mudanças, que geram atualizações. Tal condição foi observada no uso que as crianças fizeram dos brinquedos em contextos de brincadeira, com uma mescla de usos convencionais e não convencionais dos artefatos, orientados por critérios linguístico-sociais situados. Em fases no desenvolvimento infantil, as ambivalências podem demonstrar o caráter performático de tais critérios, em que o uso dos brinquedos não se dá de modo restrito ao exigido pelos padrões culturais em voga e podem indicar que novos elementos estão atuando para modificar o uso de brinquedos.

A abordagem processual da pesquisa permitiu um entendimento de como ocorre a relação entre permanência e mudança de signos na aparente desordem que mascara a complexidade dos eventos cotidianos. Ao focarmos a sequência de ações da criança brincando sozinha, observamos maior quantidade de usos não canônicos e não convencionais dos brinquedos para adaptá-los a um objeto com uso tradicional. Nas brincadeiras de cozinhar e cuidar de si, por exemplo, a bancada de ferramentas vira uma pia ou um fogão, uma ferramenta vira uma colher ou escova de dentes. Ao observarmos no brincar com a cuidadora e nas entrevistas com as mães e irmã sobre as histórias da criança e da família, identificamos as polifonias: a forma como os significados são atualizados e concretizados em brincadeiras dizem respeito às atividades presentes na história da criança, na alternância entre as forças de permanên- cia, com a produção de monologias, e mudança, com a produção do dialógico. Os movimentos de produção de significados enfatizam o papel ativo da criança na atualização da transmissão cultural bem como a importância de valorizar o imaginário infantil.

As crianças aprendem sobre os códigos de gênero mesmo antes dos três anos de idade e o estudo da relação entre cuidadoras e meninas permite vislumbrar como o discurso social estereotipado do cuidado feminino mantém sua hegemonia na vivência cotidiana, de forma a impedir que haja mudança nos papéis de gênero e nos equívocos sobre o que os homens e as mulheres podem fazer.

As origens das diferenças de posições de gênero no engajamento de atividades lúdicas estão relacionadas ao binarismo de gênero. Trata-se de processos de convencionalização constantemente atualizados em polifonias enquanto performances discursivas. Assim, as brincadeiras são consideradas tecnologias sociais, sendo possível observar mecanismos de produção do "sexo-binário" como dispositivo de poder, que visa distribuir e conservar as posições sociais em que meninos e meninas devem ocupar em nossa cultura. Jogar livremente com brinquedos, sem restrições, não alterará a identidade de gênero das crianças ou influenciará sua orientação sexual. Se mudarmos o discurso da socialização feminina em direção a uma esfera mais abrangente, talvez possamos reduzir os efeitos da desigualdade de gênero no desenvolvimento das crianças.

Pode-se vislumbrar uma educação que evidencie a heterogeneidade e as contradições dos espaços de aprendizagem tais como a escola e o contexto familiar, e direcionar o trabalho para que os sujeitos possam sentir-se livres para explorar contextos de atuação e de invenção de si, do outro e do mundo. Por isso, a necessidade de pesquisas sobre as relações entre gênero e desenvolvimento humano no início da aprendizagem informal, quando há o brincar.

A presença de contextos inclusivos de brincadeiras e a abertura das possibilidades do brincar podem preparar a criança para uma atuação concreta mais flexível a partir de perspectivas de reconhecimento do outro como parte do eu, num movimento em que a igualdade possa residir na diferença. Por outro lado, a discriminação, o processo de naturalização e os estereótipos são fabricações semióticas e se reafirmam muito mais em decorrência de um mundo simbólico, em que os comportamentos e objetos mediacionais são interpretados com base nos valores e significados que têm sido convencionalizados. 


\section{Referências}

Abbey, E., \& Valsiner, J. (2005). Emergence of meanings through ambivalence. Forum Qualitative Social Research, $6(1), 1-16$.

Arán, M. (2006). A transexualidade e a gramática normativa dos sistemas sexo-gênero. Ágora, 9(1), 49-63. https:// doi.org/10.1590/S1516-14982006000100004

Barbato, S. \& Mieto, G. (2014). O brincar, a construção de conhecimentos e a convivência. In D. N. H. Silva, \& F. S. D. Abreu (Ed.), Vamos brincar de quê? Cuidado e educação no desenvolvimento infantil (pp. 93-112). São Paulo, SP: Summus.

Barbato, S., Mieto, G., \& Rosa, A. (2016). O estudo da produção de significados em interações: Metodologias qualitativas. In M. C. S. L. Oliveira, J. F. C. Ferreira, G. S. M. Mieto, \& R. M. F. Beraldo (Ed.), Desenvolvimento humano: Cultura e educação (pp. 89-113). São Paulo, SP: Alínea.

Bartlett, F. (1996). Remembering: A study in experimental and social psychology. London: Cambridge University Press.

Benjamin, W. (2009). Reflexões sobre a criança, o brinquedo e a educação. São Paulo, SP: Editora 34.

Bicalho, C. (2013). Brincadeiras infantis e suas implicações na construção de identidades de gênero. Revista Médica de Minas Gerais, 23 (suppl 2), 41-49.

Bigler, R. S. (1997). Conceptual and methodological issues in the measurement of children's sex typing. Psychology of Women Quarterly, 21, 53-69.

Bruner, J. (1997). Atos de significação. Porto Alegre, RS: Artes Médicas.

Butler, J. (1993). Bodies that matter, on discursive limits of sex. New York NY: Routledge.

Butler, J. (2013). Incursões sexuais. In I. C. F. Passos (Ed.), Poder, normalização e violência: incursões foucaultianas para a atualidade (2a ed., pp. 91-108). Belo Horizonte, MG: Autêntica.

Correia, M. F. B., \& Meira, L.R. L. (2008). Explorações acerca da construção de Significados na Brincadeira Infantil. Psicologia: Reflexão e Crítica, 21(3), 356-364. https://doi.org/10.1590/S0102-79722008000300003.

Cowan, G., \& Hoffman, C.D. (1986). Gender stereotyping in young children: Evidence to support a concept-learning approach. Sex Roles, 14(3-4), 211-224. https://doi.org/10.1007/BF00288250

Cruz, L. M., Silva, Z. G., \& Souza, M. L. (2012). O brinquedo e a produção do gênero na educação infantil. In Anais do Seminário Nacional de Educação, Diversidade Sexual e Direros Humanos. Recuperado de http://www.periodicos.ufes.br/gepss/article/download/3880/3095

Fagundes, T. (2001). Educação e construção da identidade de gênero. In T. Fagundes (Ed.), Ensaios sobre gênero e educação (pp. 13-17), Salvador., BA: Edufba.

Fausto-Sterling, A. (2012). Sex/gender: Biology in a social world. New York, NY: Routledge.

Fausto-Sterling, A., Coll, C. G., \& Lamarre, M. (2012). Sexing the baby: Part 2 Applying dynamic systems theory to the emergences of sex-related differences in infants and toddlers. Social Science \& Medicine, 74(11), 1693-1702. https://doi.org/10.1016/j.socscimed.2011.06.027

Foucault, M. (1988). A história da sexualidade: A vontade de saber. São Paulo, SP: Graal.

Foucault, M. (2012). Microfísica do poder. São Paulo, SP: Graal.

Furlan, C. C., \& Müller, V. R. (2015). O brincar e as relações de gênero: Reflexões de crianças e docentes. Educação (UFSM), 40(3), 711-722. https://doi.org/10.5902/1984644413728

Lauretis, T. (1987). The technology of gender. Indiana: University Press.

Mieles, M. D., \& García, M. C. (2010). Apuntes sobre socialización infantil y construcción de identidad en ambientes multiculturales. Revista Latinoamericana de Ciencias Sociales, Niñez y Juventud, 8(2), 809-819.

Monteiro, C., \& Zanello, V. (2015). Tecnologias de gênero e dispositivo amoroso nos filmes de animação da Disney. Revista Feminismos, 3(1), 36-44.

Navarro, R., Martinez, V., Yubero, S., \& Larrañaga, E. (2014). Impact of gender and the stereotyped nature of illustrations on choice of color: Replica of the study by Karniol (2011) in Spanish sample. Gender Issues, 31, 142-162. https://doi.org/10.1007/s12147-014-9122-1 
Palacios, P., \& Rodríguez, C. (2015). The development of symbolic uses of objects in infants in a triadic context: a pragmatic and semiotic perspective. Infant and Child Development, 24(1), 23-43. https://doi.org/10.1002/ icd.1873

Palacios, P., Rodríguez, C., Méndez-Sánchez, C. \& Hermosillo-de la Torre, A. E. (2013). Contextos comunicativos e interactivos triádicos: la unidad básica de la educación. In, P. Palacios, M. Farfán, C. E. Navarrete, \& S.C. Miramontes (Ed.), Psicología educativa: Reflexión, práctica e intervención, (pp. 14-40). Mexico. DC: Ed. UAM.

Robinson, C. C., \& Morris, J. T. (1986). The gender-stereotyped nature of Christmas toys received by 36-, 48-, and 60-months-old children: a comparison between nonrequested vs requested toys. Sex Roles, 13(1-2), 21-32.

Rodríguez, C. (2012). El adulto como guía: ¿el eslabón perdido de desarrollo temprano? Padres y Maestros/Journal of Parents and Teachers, 344, 23-26.

Rubin, G. (1997). The traffic in women: notes on the "political economy" of sex. In L. Nicholson (Org.), The second wave: A reader in feminist theory (pp. 27-62). New York, NY: Routledge.

Sprung, B. (1983). Beginning equal: the project on nonsexist childrearing. Day Care and Early Education, 11(2), 6-8.

Volosinov, V.N. (2009). Marxismo e filosofia da linguagem. São Paulo, SP: Hucitec.

Vygotsky, L. (1978). Interaction between learning and development. Readings on the Development of Children, 23 (3), 34-41.

Wong, W. I., \& Hines, M. (2015). Preferences for pink and blue: The development of color preferences as a distinct gender-typed behavior in toddlers. Arch Sex Behavior, 44(5), 1243-1254. https://doi.org/10.1007/s10508-0150489-1

Zanello, V., \& Gomes, T. (2011). Xingamentos masculinos: a falência da virilidade e da produtividade. Caderno Espaço Feminino, 23(1-2), 263-278.

\section{André Pereira dos Santos}

Psicólogo pela Universidade de Brasília (UnB), Brasília - DF. Brasil. Graduando em Filosofia pela UnB.

E-mail: andrepstos@gmail.com

\section{Silviane Bonaccorsi Barbato}

Doutora. Pesquisadora do Departamento de Psicologia Escolar e do Desenvolvimento no Instituto de Psicologia da Universidade de Brasília (UnB), Brasília - DF. Brasil.

E-mail: silviane.barbato@gmail.com

\section{Polianne Delmondez}

Doutora e Mestre em Psicologia pelo Programa de Pós-graduação em Processos de Desenvolvimento Humano e Saúde (PG-PDS) da Universidade de Brasília (UnB), Brasília - DF. Brasil.

E-mail: polianne.delmondez@gmail.com

Endereço para envio de correspondência:

Universidade de Brasília, Campus Universitário Darcy Ribeiro, Instituto Central de Ciências Sul, Instituto de Psicologia, Laboratório Ágora Psyqué. Asa Norte. CEP: 70904-970. Brasília - DF. Brasil.

Este trabalho foi apoiado pelo CNPq e pelos Decanatos de Ensino de Graduação e de Pós-Graduação da Universidade de Brasília

Recebido 21/06/2017

Reformulado $30 / 11 / 2017$

Aprovado 21/02/2018 
Psicologia: Ciência e Profissão Out/Dez. 2018 v. 38 n4, 758-772.

Received 06/21/2017

Reformulated 11/30/2017

Approved 02/21/2018

Recibido 21/06/2017

Reformulado 30/11/2017

Aceptado 21/02/2018

Como citar: Santos, A. P., Barbato, S. B., \& Delmondez, P. (2018). Polifonia na produção do binarismo de gênero em brincadeiras na primeira infância. Psicologia: Ciência e Profissão, 38(4), 758-772.

https://doi.org/10.1590/1982-3703002302017

How to cite: Santos, A. P., Barbato, S. B., \& Delmondez, P. (2018). Polyphony in the production of gender binarism in early childhood play. Psicologia: Ciência e Profissão, 38(4), 758-772. https://doi.org/10.1590/1982-3703002302017

Cómo citar: Santos, A. P., Barbato, S. B., \& Delmondez, P. (2018). Polifonía en la producción del binarismo de género en juegos en la primera infancia. Psicologia: Ciência e Profissão, 38(4), 758-772. https://doi.org/10.1590/1982-3703002302017 